\title{
Retinopathy of prematurity blindness worldwide: phenotypes in the third epidemic
}

This article was published in the following Dove Press journal:

Eye and Brain

19 May 2016

Number of times this article has been viewed

\author{
Graham E Quinn \\ Division of Ophthalmology, \\ The Children's Hospital of \\ Philadelphia, Wood Center, \\ Philadelphia, PA, USA
}

Correspondence: Graham E Quinn Division of Ophthalmology, The Children's Hospital of Philadelphia, Wood Center, Ist Floor, Philadelphia, PA 19104, USA

Tel + I 215590279 |

$\mathrm{Fax}+\mathrm{I} 2674265015$

Email quinn@email.chop.edu
Abstract: Blindness due to retinopathy of prematurity (ROP) is an increasing problem worldwide as improved levels of neonatal care are provided in countries with developing neonatal intensive care units. The occurrence of ROP blindness varies dramatically with the socioeconomic development of a country. In regions with high levels of neonatal care and adequate resources, ROP blindness is largely restricted to premature infants with very low birth weight and low gestational age while in middle- and low-income countries with regional variation in technology and capacity, limited health resources may well limit the care of the premature newborn.

Keywords: ROP, international, blindness

\section{Introduction}

Control of childhood blindness is a priority for the World Health Organization Vision 2020 effort. ${ }^{1}$ Among the causes of blindness that are avoidable and/or treatable, retinopathy of prematurity (ROP) leads as a cause where an impact could be made by using a multidisciplinary approach and collaboration among stakeholders, including physicians, nurses, other caregivers, hospital administrators, and parents. The occurrence of severe ROP (defined here as ROP requiring treatment, ie, Type 1 ROP as defined in 2003 in the early treatment for ROP study ${ }^{2}$ ), which may result in blindness, varies dramatically with the level of neonatal and ophthalmologic care given in neonatal intensive care units (NICUs), which in turn depends on the socioeconomic development of a country. Lawn et $\mathrm{al}^{3}$ noted that there are $\sim 15$ million infants born prematurely each year with 1.2 million born in high-income countries with access to full neonatal intensive care, another 8.2 million born in middle-income or low-income countries with access to hospital births but perhaps in hospitals with limited space, staff, and equipment, and 5.6 million born in low-income countries with home birth and care at home and therefore a limited chance of survival.

In high-income countries, the level of neonatal care in premature infants is generally excellent due to the availability of economic and technological resources and adequate personnel. ROP-associated blindness is relatively uncommon and accounts for $<10 \%$ of individuals with blindness. ${ }^{4,5}$ However, in middle- and low-income countries with regional variation in technology and capacity, limited health resources may well limit the care of the premature newborn as the survival of smaller and less mature infants increases. ${ }^{6}$ In these regions, ROP blindness may account for up to $40 \%$ of blindness. However, the care given may vary widely in these regions, countries, and even within cities. ${ }^{7,8}$ In these regions, more mature and larger birth weight infants may 
well develop ROP blindness as experience in the care of these infants develops. This results in a much greater percentage of childhood blindness up to $40 \%$ due to limited resources and expertise. ${ }^{6}$

There have been three distinct periods that could be termed ROP "epidemics". In the 1940s and early 1950s, ROP blindness was first observed and was related to unrestricted oxygen administration with no means of monitoring its use. Infants under 1,000 $\mathrm{g}$ birth weight rarely survived during this period, and some larger, more mature infants were blinded. Once the association of ROP with oxygen was recognized and its use restricted, fewer infants had ROP blindness and there was an unfortunate increase in mortality, likely due to the restricted oxygen administration. ${ }^{9}$ By the late 1960 s and 1970 s, monitoring of oxygen saturation had been developed as had numerous other advances in neonatal care in countries with well-developed neonatal units. This resulted in the increased survival of smaller, less mature infants, in particular those $<1,000 \mathrm{~g}$. However, this increased survival resulted in ROP blindness, despite the improvements in technology and knowledge. ${ }^{10}$

A third epidemic developed, first recorded in the 1990s, when ROP blindness was increasingly observed in countries developing neonatal intensive care. This included the People's Republic of China, South America, Eastern Europe, Russia, and countries in South and Southeast Asia. Based on the data from 2010, Blencowe et al $^{11}$ estimated that there were $\sim 2.6$ million premature infants born with gestational ages of $<32$ weeks and calculated that the acute phase ROP varied from $\sim 20 \%$ in countries with very low neonatal mortality rates ( $<5$ per thousand births) to nearly $40 \%$ in countries with greater mortality rates. An estimated 20,000 infants had severe visual impairment or blindness with almost half as many again with mild or moderate impairment. Figure 1 shows the findings of Blencowe et $\mathrm{al}^{11}$ study based on regional differences. The size of the circle indicates the size of the premature population born in each region. Within the circle, the darker wedge indicates the proportion of the population that is blind or severely visually handicapped. From these circles, it is clear that the majority of visually impaired survivors were born in middle-income regions of Latin America, East and South Asia, Eastern Europe, and Central Asia. Since optimal neonatal care and effective ROP detection and treatment programs are still being developed in these regions, there are opportunities for preventive interventions from both neonatal care and ophthalmological perspectives. ${ }^{6,12}$ It is important to recall that not all infants who develop some stage of ROP will become blind or visually impaired. ${ }^{5}$ The most recent large clinical trial of treatment was the early treatment for ROP trial conducted in 26 clinical centers in the USA. ${ }^{5}$ Infants with $<1,251 \mathrm{~g}$ birth weight were enrolled and approximately two-third of infants developed some stage of ROP. Less than $10 \%$ of enrolled infants developed ROP severe enough to consider treatment, and this trial determined

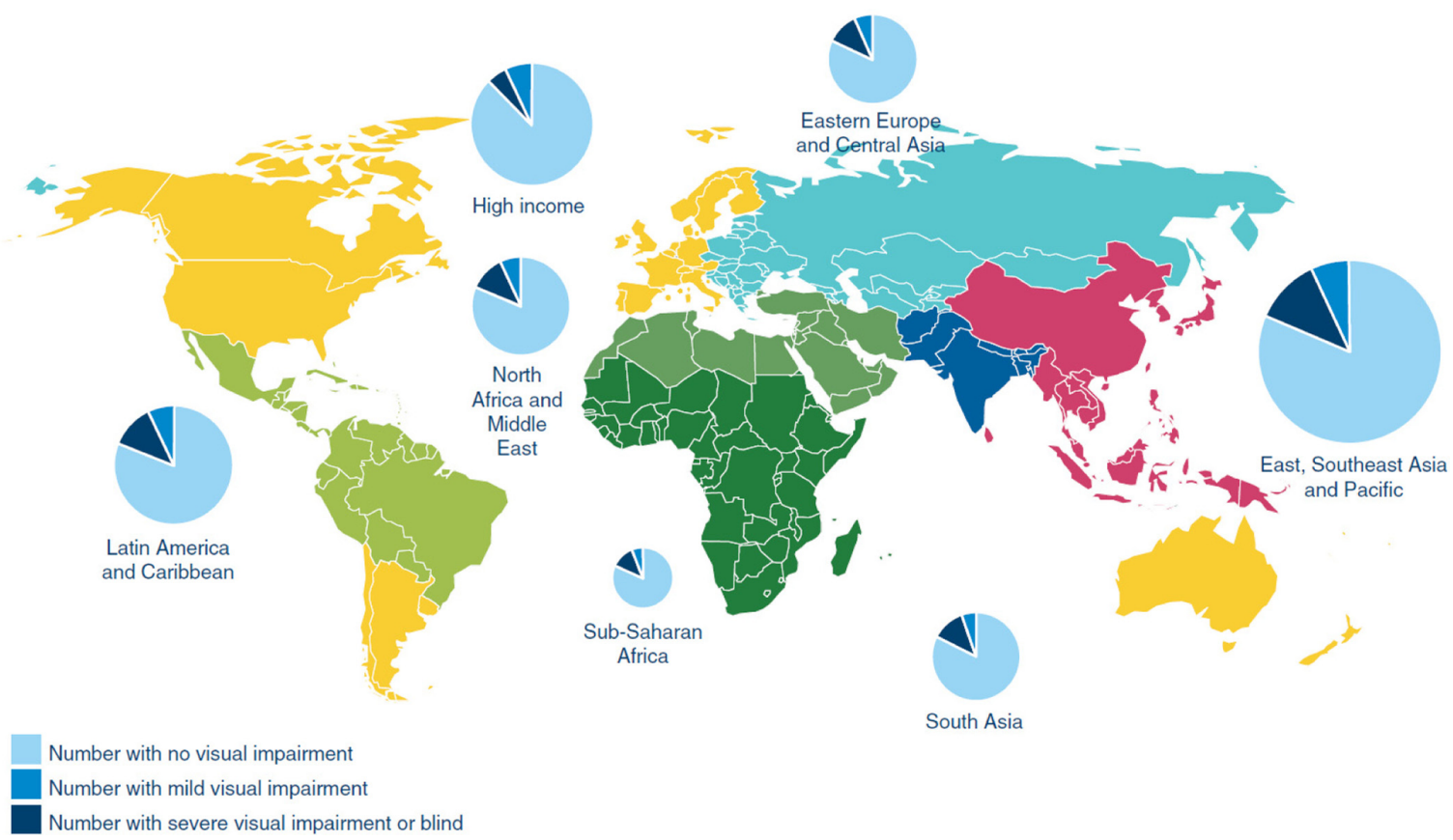

Figure I Burden by world region of retinopathy of prematurity related visual impairment among premature infants born in 2010 and surviving the neonatal period. Note: Reproduced from Blencowe H, Lawn JE, Vazquez T, et al. Preterm-associated visual impairment and estimates of retinopathy of prematurity at regional and global levels for 2010. Pediatr Res. 2013;74(1):35-49."' 
that peripheral retinal ablation of eyes with zone I ROP with plus disease, zone I stage 3 ROP without plus disease, or zone II stage 2 or 3 ROP with plus disease all benefited from the treatment. Eyes with these ROP findings were classified as having "Type 1" ROP. Among the treated eyes, only 14.5\% had an "unfavorable" visual acuity at 9 months after term and the remainder had functional acuity. Visual acuity was measured using Teller acuity cards, and unfavorable was defined as worse than four standard deviations below the normal value for age, ie, very poor or blind. This level of ROP severity is the current indication for the treatment of established acute phase ROP, and its relatively low incidence means that detecting those few infants who develop ROP needing treatment is time and personnel intensive, even in regions of the world with excellent neonatal care.

\section{ROP detection programs}

There are several important aspects of ROP natural history that are essential parts of planning effective detection programs. One of the most useful aspects is that the infants who develop ROP severe enough to require treatment are almost always still in the hospital and are therefore accessible to caregivers. The onset of ROP in most of the infants is $\sim 32$ weeks postmenstrual age (PMA), and the most severe disease occurs in the 35-39-week PMA period. ${ }^{13}$ Larger, more mature infants do tend to develop ROP at a bit earlier PMA than the very low birth weight group. ${ }^{14}$ However, in terms of defining what population of premature infants needs to be examined, the criteria needed to detect those with severe ROP vary substantially based on the level of neonatal care in the region. These criteria must be developed locally based on the data on infants screened and treated in a country, and in the absence of data, imposing very broad birth weight and gestational age criteria is an essential first step with the aim to narrow the criteria as significant amounts of data are accumulated. Narrowing the birth weight and gestational age guidelines without sufficient supporting data may put some marginally larger, more mature prematures at risk of being missed when a serious disease is present.

In general, the reliable assessment of birth weight and gestational age for an infant is available at the time of birth, and in most countries, these criteria are used to determine which infants and when these infants need to be examined. ${ }^{15}$ In the UK, the current guidelines used to determine which infants must be examined are those with $<1,251 \mathrm{~g}$ birth weight or $<31$ weeks gestational age. ${ }^{16}$ Slightly larger (up to $1,500 \mathrm{~g}$ ) or more mature infants (up to 32 weeks gestation) are also eligible. In the USA, the criteria are infants with $<31$ weeks of gestational age or $<1,500 \mathrm{~g}$ birth weight and also more mature or larger birth weight infants who have an "unstable" clinical course. ${ }^{17}$

Figure 2A shows the birth weight and gestational age of infants from NICUs in the UK, the US, and Canada who were reported to have treated for severe ROP or had stage 4 or stage 5 ROP in the early 2000s. All but one infant fell within the UK criteria for screening examination. The mean birth weight of these infants was $<800 \mathrm{~g}$, and the mean gestational age was $<26$ weeks.

In contrast, Figure $2 \mathrm{~B}$ provides the birth weight and gestational age of infants using the same ROP status as Figure 2A also in the early 2000s from eight middle-income countries and two low-income countries. Again, the UK criteria are presented in the figure. The mean birth weight of these infants was $>1,000 \mathrm{~g}$ in all the represented countries, except Chile (903 g) and Brazil (952 g). Similarly, the mean gestational age for each country ranged from just $>26$ to 35 weeks. For these countries, $13 \%$ of the infants had birth weights or gestational ages that exceeded the criteria used in the UK. Moreover, from Figures 1 and 2, it is reasonable to hypothesize that the infants in the lower left quadrant of Figure 2A from middle- and low-income countries likely received excellent care similar to the infants in that quadrant in high-income countries.

These two figures emphasize the importance of developing screening criteria appropriate to the population of premature infants being cared for in various countries. Some countries have elected to have wide criteria until sufficient data are collected. For example, $<34$ weeks gestational age and $<2,000 \mathrm{~g}$ birth weight were often used as an initial starting guideline with the aim to revise as needed.

It is also apparent from Figures 2 and 3 that the current "third" epidemic reflects both conditions from the "first" epidemic in which there was unrestricted use of oxygen supplementation and the "second" epidemic where prematurity was a major contributor to morbidity. ${ }^{6}$ This situation highlights the need for increased awareness of this potentially blinding disease and careful monitoring of risk factors, including oxygen administration. Increased surveillance and further attention to equipment, personnel, and training in ophthalmology, neonatology, and nursing will not eliminate blindness due to ROP but will decrease its incidence.

\section{Development of ROP blindness prevention programs}

There are four key components that need attention as ROP detection and treatment programs develop in middle- and low-income countries. They are: 1) epidemiologic and 

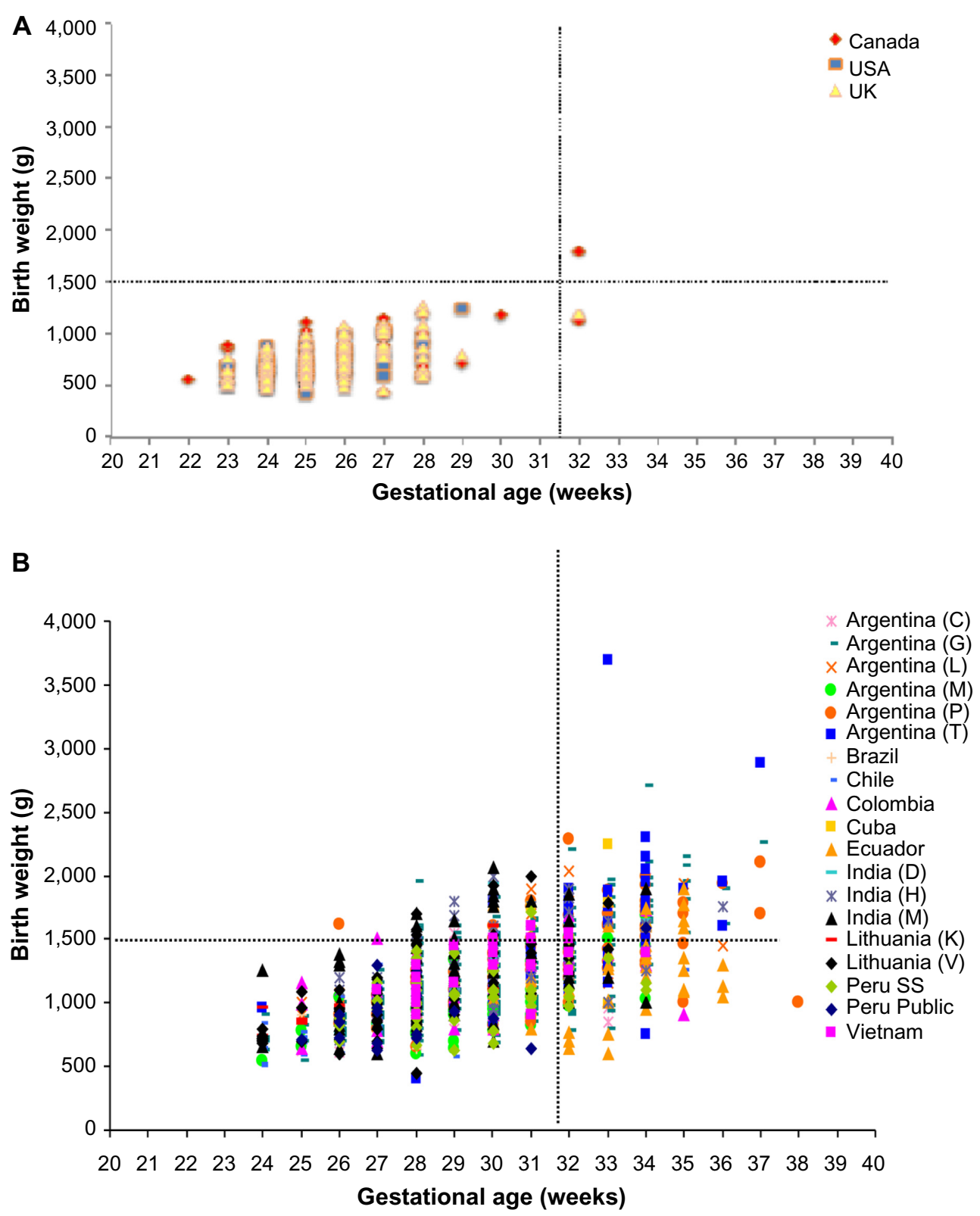

Figure 2 Birth weight and gestational age of infants with threshold disease or worse from three high income countries (A); and low/middle income countries (B) in 1996-2002. Notes: The horizontal line indicates the boundaries of the United Kingdom screening data. The letters in brackets refer to different regions or cities within a country. Reproduced with permission from Pediatrics, ; I 5:e5I8-e525, Copyright (C 2005 by the AAP. Gilbert C, Fielder A, Gordillo L, et al. Characteristics of infants with severe retinopathy of prematurity in countries with low, moderate, and high levels of development: implications for screening programs. ${ }^{6}$

Abbreviations: GA, gestational age; ROP, retinopathy of prematurity.

health systems research as outlined briefly earlier; 2) building effective teams of caregivers within the institution; 3) improving local capacity in terms of personnel, equipment, and education; and 4) partnerships between institutions. Financial support for the latter is often initiated by nongovernmental institutions such as Orbis, Christoffel Blindenmission, Pan American Health Organization, and the International Agency for the Prevention of Blindness among many others. However, for sustaining programs in the long run, support from the governmental agencies is essential.
Building effective teams and improving local capacity are intimately intertwined and require extensive planning and support within the target region. ROP workshops have proven as an effective way to accomplish these two components. The purpose of the workshops is to use the experience and expertise of participants to plan efficient and effective programs for the control of blindness due to ROP. Workshops are led by in-country leaders in the effort and often assisted by international ROP experts. The objectives of a 2-3-day workshop are to understand the current ROP situation, to 
develop or improve national guidelines, to institute the use of common forms for ROP and neonatal data, and to develop short- and long-term goals. This approach has proven to be effective in developing and improving programs in Latin America over the last 15 years, with both Latin American workshops (in which many countries participated) and single country or regional efforts. For example, a Latin America workshop was held in Lima, Peru, in 2005 with participation from 19 countries in Latin America and the Caribbean. There were ROP detection and treatment programs in most of the countries, but five countries had no current program. Since that time, with extensive effort and support, all five countries have developed programs and others have improved their programs. However, the effort to move forward can be spasmodic. The effort depends on more than just the ophthalmologists, nurses, and neonatologists participating in the workshops. Local and national ministries of health depend on a stable government for support, a condition that is sometimes not the case with frequent changes in administrators and administrations.

One clear example of the benefits of team building is highlighted in a Caribbean island nation. In 2005, there was no ROP detection or treatment program, but shortly afterward, a program was started in this country with 230,000 births annually at that time. By the time of an in-country workshop in 2007, a program had been started, and the workshop participants agreed to national guidelines for ROP screening: $<2,500 \mathrm{~g}$ birth weight or $<37$ weeks gestational age. The participants also agreed on using a standard reporting form, increasing awareness through advocacy with hospital administrations, the Ministry of Health, and other stakeholders including parents of premature infants. Further training for caregivers was planned. In a follow-up workshop just 15 months later, three regional referral treatment centers had been established, each with laser equipment for the treatment of severe disease. ROP had been recognized as an important cause of blindness by the Societies of Ophthalmology and Pediatrics, and a law requiring ROP examinations for premature infants who fell within the guidelines was being proposed. Data were available for seven NICUs, ${ }^{18}$ and $>600$ infants with gestational ages of $<37$ weeks had been examined. ROP was noted in $30 \%$ of the examined infants with a treatment required in $13 \%$. Among those treated, there were infants with birth weights of 2,060, 2,265, 2,500, and 2,627 g. Work has continued in this region.

One of the critical components of an effective ROP program is adequate personnel and equipment. This was highlighted by
Zin et $\mathrm{al}^{8}$ in 2010 in six NICUs of Rio de Janeiro. The rate of ROP requiring treatment varied from $4 \%$ in a nursery with an infant to nurse ratio of $2: 1$ compared to a $12 \%$ treatment rate in a nursery with an infant to nurse ratio of $17: 1$ and a $9 \%$ treatment rate in a nursery with an infant to nurse ratio of $8: 1$. Similarly, Gordillo et a ${ }^{19}$ documented in 2012 that there were more than four times more infants on supplemental oxygen than there were oxygen analyzers available for monitoring therapy. Such conditions set up the likelihood of first epidemic ROP blindness, and addressing these conditions is an ongoing struggle in many of the NICUs in middle- and low-income countries.

\section{Summary for control of ROP blindness}

A multidisciplinary approach is essential to address the needs of premature infants in middle- and low-income countries as they develop neonatal intensive care. Education should be imparted to health care personnel with adequate training to care for the premature infants. Adequate equipment is needed for neonatal and ophthalmologic care. Specific protocols are needed for determining which infants need to be evaluated as well as for continued monitoring of results with standard databases. To be effective and sustained, there must be governmental support. In addition, collaborations among individuals (international and in-country) are needed with the involvement of national societies and other professional organizations. The involvement of parents and other members of the public enhances the awareness and increases the likelihood of a sustained effective effort.

\section{Acknowledgment}

The author would like to acknowledge the critical contributions of Clare Gilbert, Brian Darlow, Andrea Zin, Luz Gordillo and many others to this effort.

\section{Disclosure}

The author reports no conflicts of interest in this work.

\section{References}

1. WHO. Global Initiative for the Elimination of Avoidable Blindness. WHO, Geneva; 1997. WHO/PBL/9761.

2. Early Treatment for Retinopathy Of Prematurity Cooperative Group. Revised indications for the treatment of retinopathy of prematurity: results of the early treatment for retinopathy of prematurity randomized trial. Arch Ophthalmol. 2003;121:1684-1694.

3. Lawn JE, Davidge R, Paul VK, et al. Born too soon: care for the preterm baby. Reprod Health. 2013;10(Suppl 1):S5.

4. Rahi JS, Cable N. Severe visual impairment and blindness in children in the UK. Lancet. 2003;362:1359-1365. 
5. Good WV. Final results of the early treatment for retinopathy of prematurity (ETROP) randomized trial. Trans Am Ophthalmol Soc. 2004; 102:233-248.

6. Gilbert C, Fielder A, Gordillo L, et al. Characteristics of infants with severe retinopathy of prematurity in countries with low, moderate, and high levels of development: implications for screening programs. Pediatrics. 2005;115:e518-e525.

7. Zin A, Gole GA. Retinopathy of prematurity-incidence today. Clin Perinatol. 2013;40:185-200.

8. Zin AA, Magluta C, Pinto MF, et al. Retinopathy of prematurity screening and treatment cost in Brazil. Rev Panam Salud Publica. 2014; $36: 37-43$.

9. Cross CW. Cost of preventing retrolental fibroplasia. Lancet. 1973;2: 954-956.

10. Lucey JF, Dangman B. A reexamination of the role of oxygen in retrolental fibroplasia. Pediatrics. 1984;73:82-96.

11. Blencowe H, Lawn JE, Vazquez T, et al. Preterm-associated visual impairment and estimates of retinopathy of prematurity at regional and global levels for 2010. Pediatr Res. 2013;74(Suppl 1):35-49.

12. Gilbert C. Retinopathy of prematurity: a global perspective of the epidemics, population of babies at risk and implications for control. Early Hum Dev. 2008;84:77-82.
13. Cryotherapy for Retinopathy of Prematurity Cooperative Group. Incidence and early course of retinopathy of prematurity. Ophthalmology. 1991;98:1628-1640.

14. Quinn G, Johnson L, Abbasi S. Onset of retinopathy of prematurity as related to postnatal and postconceptional age. $\mathrm{Br} J$ Ophthalmol. 1992;76:284-288.

15. Reynolds JD, Dobson V, Quinn GE, et al. Evidence-based screening criteria for retinopathy of prematurity: natural history data from the CRYO-ROP and LIGHT-ROP studies. Arch Ophthalmol. 2002;120: $1470-1476$

16. Wilkinson AR, Haines L, Head K, et al. UK retinopathy of prematurity guideline. Early Hum Dev. 2008;84:71-74.

17. Fierson WM. Screening examination of premature infants for retinopathy of prematurity. Pediatrics. 2013;131:189-195.

18. Zin AA, Moreira ME, Bunce C, et al. Retinopathy of prematurity in 7 neonatal units in Rio de Janeiro: screening criteria and workload implications. Pediatrics. 2010;126:e410-e417.

19. Gordillo L, Villanueva AM, Quinn GE. A practical method for reducing blindness due to retinopathy of prematurity in a developing country. J Perinat Med. 2012;40:577-582.
Eye and Brain

\section{Publish your work in this journal}

Eye and Brain is an international, peer-reviewed, open access journal focusing on clinical and experimental research in the field of neuroophthalmology. All aspects of patient care are addressed within the journal as well as basic research. Papers covering original research, basic science, clinical and epidemiological studies, reviews and evaluations,

\section{Dovepress}

guidelines, expert opinion and commentary, case reports and extended reports are welcome. The manuscript management system is completely online and includes a very quick and fair peer-review system, which is all easy to use. Visit http://www.dovepress.com/testimonials.php to read real quotes from published authors. 